\title{
Pediatric multisystem SARS COV2 with versus without cardiac involvement: a multicenter study from Latin America
}

\author{
Ricardo Pignatelli ${ }^{1}$. Clara Vazquez Antona ${ }^{2}$. Ivan Romero Rivera ${ }^{3}$. Patricia Alvarez Zenteno ${ }^{4} \cdot$ Yanet Toribio Acosta ${ }^{5}$. \\ Manuel Huertas-Quiñones ${ }^{6}$. Carlos Alvarez Murillo ${ }^{7}$. Franklin Mendoza Torres ${ }^{7}$. Carlos Fernandez Cabalin ${ }^{8}$. \\ Ana Galván Camacho ${ }^{9}$ - Alex Alcántara Pérez ${ }^{10}$ - Ana Braga Lombardi ${ }^{11}$ • Andressa Mussi Soares ${ }^{12}$. \\ Carolina Torres Garcia ${ }^{13}$. Cibelle Teixeira Borges ${ }^{14}$. Claudia Natalia Villalba ${ }^{15}$. Cristhian Ramírez Lechado ${ }^{16}$. $^{2}$ \\ Deborah Trevisan Dias ${ }^{17}$. Diana Aravena Morales ${ }^{18}$. Elizabeth Mora Copete ${ }^{19}$. Guillermo Larios Goldenberg ${ }^{20}$. \\ Jahaira Sussety Salazar ${ }^{21}$ • Jessica Alchundia Moreira ${ }^{21}$ • Junko Asakura ${ }^{22}$ • Karla Solórzano Sabando ${ }^{21}$. \\ Klebia Castello Branco ${ }^{23}$. Lida Toro Rosas ${ }^{10}$. Magna Pereira Duarte ${ }^{24}$. María Jiménez Carbajal ${ }^{25}$. \\ Martha Rubio Hernandez ${ }^{26}$. Moisés Mier Martínez ${ }^{27}$. Nancy Garay Echeverría ${ }^{28}$. Olga Maza Caneva ${ }^{29}$. \\ Patricia Romero Sepulveda ${ }^{30}$. Paulina Agurto Díaz ${ }^{18}$. Ruth Rugel Plúas ${ }^{31}$ - Theo Contreras Alvarado ${ }^{32}$. \\ Lorena Tapia Faundes $^{33}$. Yeny Briones Diaz ${ }^{18}$. Justin P. Zachariah ${ }^{1}$ (D)
}

Received: 9 February 2021 / Revised: 18 March 2021 / Accepted: 21 March 2021 / Published online: 1 April 2021

(C) The Author(s), under exclusive licence to Springer-Verlag GmbH Germany, part of Springer Nature 2021

\begin{abstract}
Latin America (LATAM) children offer special insight into Severe Acute Respiratory Syndrome Coronavirus 2 (SARS COV2) due to high-risk race/ethnicity, variability in medical resources, diverse socioeconomic background, and numerous involved organ systems. This multinational study of LATAM youth examined the distinguishing features of acute or late multisystem SARS COV2 with versus without cardiac involvement. A consecutive sample of youth 0-18 years old ( $N=98 ; 50 \%$ male) presenting with multisystem SARS COV2 to 32 centers in 10 Latin American countries participating in a pediatric cardiac multi-imaging society were grouped as with versus without cardiac involvement, defined as abnormal echocardiographic findings or arrhythmia. Collected clinical data were analyzed by Student's $t$ test or Fisher's exact test. Cardiac $(N=48,50 \%$ male) versus no cardiac $(N=50,50 \%$ male) were similar in age; weight; nonrespiratory symptoms; and medical history. The cardiac group had 1 death and symptoms including coronary artery dilation, ejection fraction $<50 \%$, pericardial effusion, peripheral edema, arrhythmia, and pulmonary artery thrombus. The cardiac group had higher risk of ICU admission (77\% vs 54\%, $p=0.02)$; invasive ventilation ( $23 \%$ vs $4 \%, p=0.007)$; vasoactive infusions $(27 \%$ vs $4 \%, p=0.002)$; prominent respiratory symptoms ( $60 \%$ vs $36 \%, p<0.03)$; abnormal chest imaging ( $69 \%$ vs $34 \%, p=0.001)$; troponin $(33 \%$ vs $12 \%, p=0.01)$; alanine aminotransferase ( $33 \%$ vs $12 \%, p=0.02)$; and thrombocytopenia ( $46 \%$ vs $22 \%, p=0.02$ ). Receiver operating curve analysis showed that abnormal laboratories had $94 \%$ sensitivity and $98 \%$ negative predictive value on the need for ICU interventions.

Conclusion: In LATAM children with multisystem SARS COV2, cardiac involvement was prevalent. Cardiac involvement was more likely to require ICU interventions, certain abnormal labs, and respiratory involvement.

\section{What is Known:}

- SARS COV2 can be asymptomatic in children but in some cases can have serious multisystemic involvement.

- Hispanic ethnicity is purportedly at high risk of SARS COV2 in nations where they are often disadvantaged minority populations.

What is New:

- Latin American children presenting with multisystem SARS COV2 frequently have cardiac involvement which was associated with ICU interventions; prominent respiratory symptoms; abnormal chest X-ray; elevated troponin, ALT, and thrombocytopenia.

- Elevated troponin, ALT or thrombocytopenia had high sensitivity and negative predictive value on the need for intensive care interventions.
\end{abstract}

Communicated by Peter de Winter

Justin P. Zachariah

justin.zachariah@bcm.edu

Extended author information available on the last page of the article 
Keywords Pediatric cardiology $\cdot$ Coronary aneurysm $\cdot$ Myocarditis $\cdot$ SARS COV2

$\begin{array}{ll}\text { Abbreviations } & \\ \text { BNP } & \text { Brain natriuretic peptide } \\ \text { ICU } & \text { Intensive care unit } \\ \text { IVIg } & \text { Intravenous immunoglobulin } \\ \text { LATAM } & \text { Latin America } \\ \text { LV } & \text { Left ventricular } \\ \text { MISC } & \text { Multisystemic inflammatory syndrome in } \\ & \text { children } \\ \text { PIMS } & \text { Pediatric inflammatory multisystem syndrome } \\ \text { REDCap } & \text { Research Electronic Data Capture } \\ \text { ROC } & \text { Receiver operator curve } \\ \text { S A R S } & \begin{array}{l}\text { Severe Acute Respiratory Syndrome } \\ \text { COV2 }\end{array} \\ \end{array}$

\section{Introduction}

The novel severe acute respiratory syndrome coronavirus 2 (SARS COV2) emerged widely in December 2019 and has since become a worldwide pandemic [1-3]. Rarely, children are severely infected with multisystem involvement beyond the respiratory tract including gastrointestinal, skin, coagulation, and cardiovascular complications. This multisystem involvement may occur during acute infection or later in a new-to-medicine syndrome called PIMS (pediatric inflammatory multisystem syndrome) or MISC (multisystem inflammatory syndrome in children) [4]. Risk factors for severe consequences include aggregate factors associated with general infection spread such as healthcare system prevention programs, availability of medical interventions, socioeconomic freedom to socially distance, availability of mitigation paraphernalia, and competing health risks like alternate infections, while individual factors include race/ethnicity and past medical history factors like obesity, heart disease, cancer, and immunocompromised status [1-3]. Recent reports highlight Hispanic ethnicity as a high risk [5].

More primary data collection to guide clinical management of acute SARS COV2 or PIMS/MISC in youth is needed to formulate management responses, especially for potentially lifethreatening cardiovascular complications. The need is even more acute particularly for resource-poor settings in order to identify adequate strategies and reduce unnecessary practice variation. Further disambiguation is needed between Latin American ethnicity versus other risk factors such as obesity or socioeconomic status in high per capita income countries. While previous reports have arisen from locations with high-resource medical settings like the USA and UK, health options and economic reality are quite different for SARS COV2-affected children in LATAM including from individual-specific factors intrinsic ranging to community disparities up to sociopolitical variation in response to SARS COV2. Given the variability of presentation, evolving disease definitions, and focus on symptomatic support during the advent of SARS COV2, we focused on more seriously affected LATAM children early in the pandemic presenting with high suspicion for SARS COV2. Within this group, we searched for widely assayable clinical symptoms, signs, and diagnostic investigations that would be useful to providers in variably resourced settings. This multicenter study reports the reality of multisystem, acute, or late SARS COV2 by collating isolated clinical cases of LATAM youth from 32 centers in 10 countries of Central America, South America, and Mexico. We compared these multisymptomatic children on the basis of presence versus absence of cardiac symptoms with respect to other organ system signs and symptoms, medical history and presentation, laboratory and imaging, and therapies. To focus on those with presumed PIMS/MISC, separate sensitivity analysis was performed on those with positive SARS COV2 IGG during clinic presentation.

\section{Methods}

This study was conducted within the Society of Cardiovascular Imaging of the Interamerican Society of Cardiology (SISIAC), a voluntary conglomerate of countries from Latin America, represented by a national board member, whose mission is education and research in topics covering multiple cardiovascular imaging modalities. SISIAC members are echocardiographers, magnetic resonance imaging physicians, intensive care physicians, clinical cardiologists, and other specialists including pediatric cardiologists from Argentina, Brazil, Chile, Colombia, Dominican Republic, Ecuador, Nicaragua, Paraguay, Peru, and Mexico across 32 centers. Due to severe clinical case burdens in these highly affected locations, other pediatric specialists managing pediatric COVID cases such as pulmonologists, rheumatologists, radiologists also uploaded information.

To harmonize data collection, an online data entry form was created, and a URL was deployed to participating site providers. Included patients were of both sexes from birth up to 18 years of age with or without preexisting medical conditions. Excluded patients were those with fewer than 2 symptoms or signs endorsed by the treating provider. On this basis, 104 children from 10 nations were entered into the database, and 6 were excluded due to having only 1 symptom, leaving 98 children in this analysis. This study was institutional review board-approved and deemed exempt from consent due to the de-identified, retrospective nature of data collected.

\section{Data collection}

Research Electronic Data Capture (REDCap) was used to securely collect provider-entered data on demographic, anthropometric, 
symptoms and signs, and management (Supplementary Table 1). SARS COV2 was defined as documented SARS COV2 test positivity, close contact with documented or suspected SARS COV2 patient, or combination of symptoms/signs consistent with SARS COV2 or sequelae. Symptoms, radiological findings, laboratory signs, and clinical management were assessed as present versus absent. Symptom ascertainment used conditional organization such that 1st-tier questions included endorsement of presence of symptoms affecting the respiratory, cardiovascular, gastrointestinal, neurological, cutaneous, abnormal laboratory, or abnormal imaging. If the presence of one of these categories was endorsed, a secondary tier of specific symptoms and tests was assayed specific to the endorsed category. Past presence of serious medical history was assessed.

\section{Statistical analysis}

The primary comparison was between those patients with versus without cardiovascular involvement (cardiac vs no cardiac). The cardiac group was defined as diagnosed arrhythmia including premature atrial or ventricular contractions, sustained or nonsustained atrial or ventricular tachycardias, or atrioventricular block of any degree; dilation of any coronary artery segment above body surface area-referenced $z$ score at or above 2; LV ejection fraction below $50 \%$; dilated LV size at or above 2 scores; qualitative assessment of moderate or greater regurgitation of atrioventricular or semilunar valves; any pericardial effusion; clinical diagnosis of myocarditis by treating provider; clinical diagnosis of peripheral edema; or vascular thrombus/embolism. Continuous data (largely limited to age and weight) were analyzed using Student's $t$-test. Categorical data was analyzed using Fisher's exact test. Receiver operator curves (ROCs) were constructed using the presence of the most strongly associated laboratory tests versus the need for ICU care, specifically inotropic infusion or mechanical ventilation. Two-sided $p$ values less than 0.05 were considered significant. SPSS 25 (IBM, Chicago, IL) was used for statistical analyses.

\section{Results}

Multisystem SARS COV2 was reported from mid-May to August 2020 comprising 98 children, 48 cardiac and 50 no cardiac (Table 1). The cardiac group trended toward being younger, but otherwise similar in weight and sex. Past medical histories were similar with no obvious overrepresentation in the
Table 1 Multisystem SARS COV2 reported from mid-May to August 2020

\begin{tabular}{|c|c|c|c|}
\hline Background characteristics & $\begin{array}{l}\text { No cardiac } \\
\text { involvement }\end{array}$ & $\begin{array}{l}\text { Cardiac } \\
\text { involvement }\end{array}$ & $\begin{array}{l}p \\
\text { value }\end{array}$ \\
\hline$N$ & 50 & 48 & \\
\hline Age in years, mean (SD) & $6.1(4.3)$ & $4.4(3.9)$ & 0.06 \\
\hline Male, no. $(\%)$ & $25(50 \%)$ & $24(50 \%)$ & 1 \\
\hline Weight in kilograms, mean (SD) & $26.2(15.9)$ & $21.2(15.8)$ & 0.12 \\
\hline $\begin{array}{l}\text { Age, sex-adjusted weight percentile }>85 \% \text {, no. } \\
(\%)\end{array}$ & $14(28 \%)$ & $17(35 \%)$ & 0.52 \\
\hline No past medical conditions, no. (\%) & $32(64 \%)$ & $26(54 \%)$ & 0.41 \\
\hline \multicolumn{4}{|l|}{ History of } \\
\hline Asthma, no. (\%) & $4(8 \%)$ & $7(15 \%)$ & 0.35 \\
\hline Cancer, no. $(\%)$ & $4(9 \%)$ & $0(0)$ & 0.12 \\
\hline Complex congenital heart disease, no. (\%) & 0 & $2(5 \%)$ & 0.23 \\
\hline Diabetes mellitus, no. (\%) & 0 & 0 & \\
\hline Hypertension, no. (\%) & 0 & 0 & \\
\hline Immunomodulation, no. (\%) & $2(4 \%)$ & $2(5 \%)$ & 1 \\
\hline Prematurity 24-36 weeks gestation, no. (\%) & $1(2 \%)$ & $2(5 \%)$ & 0.61 \\
\hline Close contact SARS COV2 exposure, no. (\%) & $13(26 \%)$ & $23(48 \%)$ & 0.04 \\
\hline SARS COV2 test-positive, no. (\%) & $19(38 \%)$ & $32(67 \%)$ & 0.005 \\
\hline PCR, no. $(\%)$ & $11(22 \%)$ & $15(31 \%)$ & 0.36 \\
\hline IgM, no. $(\%)$ & $7(14 \%)$ & $11(23 \%)$ & 0.30 \\
\hline IgG, no. (\%) & $8(16 \%)$ & $15(31 \%)$ & 0.10 \\
\hline
\end{tabular}

$P$ values in bold italics indicate statistical significance $<0.05$

Immunomodulation includes patients who are immunocompromised, with solid organ transplant, and with inflammatory conditions

Abbreviations: SARS COV2 Severe Acute Respiratory Syndrome Coronavirus 2, PCR polymerase chain reaction 
cardiac group for those with asthma, cancer, congenital heart disease, diabetes mellitus, hypertension, immunomodulation (defined as on immune modifying therapies or intrinsically immunocompromised), or prematurity. Congenital heart disease was present in 2 cardiac group patients, but cardiac status worsened while infected with SARS COV2. Positive SARS testing was more likely in the cardiac group. SARS COV2 IgG indicating initial SARS COV2 exposure weeks earlier was present in similar proportions of no cardiac and cardiac patients (Table 1). One infant in the cardiac group with coronary artery dilation and left ventricular dilation died.

\section{Symptoms and signs}

Cardiac patients had significantly higher number of signs and symptoms compared to noncardiac patients (Table 2). Cardiac patients $(N=48)$ had abnormal echocardiography in $81 \%$ specifically with coronary artery dilation in $46 \%$, LV ejection fraction $<50 \%$ in $23 \%$, dilated LV in $27 \%$, moderate to severe valvar regurgitation in $21 \%$, pericardial effusion in $29 \%$, arrhythmia in $12 \%$, myocarditis diagnosis in $37 \%$, peripheral edema in $31 \%$, and pulmonary embolism in one newborn infant (Fig. 1). Cardiac patients
Table 2 Cardiac patients with significantly higher number of signs and symptoms compared to noncardiac patients

\begin{tabular}{|c|c|c|c|}
\hline Signs and symptoms & $\begin{array}{l}\text { No cardiac } \\
\text { involvement }\end{array}$ & $\begin{array}{l}\text { Cardiac } \\
\text { involvement }\end{array}$ & $\begin{array}{l}p \\
\text { value }\end{array}$ \\
\hline$N$ & 50 & 48 & \\
\hline Total count of signs and symptoms, $N$ (SD) & $6(3)$ & $10(5)$ & $<0.001$ \\
\hline Fever, no. $(\%)$ & $37(74 \%)$ & $30(63 \%)$ & 0.28 \\
\hline \multicolumn{4}{|l|}{ Cardiac symptoms } \\
\hline Abnormal echocardiography, no. (\%) & & $39(81 \%)$ & \\
\hline Coronary artery dilation, no. (\%) & & $22(46 \%)$ & \\
\hline Left ventricular ejection fraction $<50 \%$, no. $(\%)$ & & $11(23 \%)$ & \\
\hline Left ventricular dilation, no. (\%) & & $13(27 \%)$ & \\
\hline Moderate or severe valvar regurgitation, no. (\%) & & $10(21 \%)$ & \\
\hline Pericardial effusion, no. (\%) & & $14(29 \%)$ & \\
\hline Arrhythmia, no. (\%) & & $6(12 \%)$ & \\
\hline Myocarditis, no. (\%) & & $18(37 \%)$ & \\
\hline Peripheral edema, no. (\%) & & $15(31 \%)$ & \\
\hline Main pulmonary artery embolism, no. (\%) & & $1(2 \%)$ & \\
\hline Respiratory symptoms, no. (\%) & $18(36 \%)$ & $29(60 \%)$ & 0.03 \\
\hline Accessory respiratory muscle use, no. (\%) & $6(13 \%)$ & $16(37 \%)$ & 0.01 \\
\hline Neurological symptoms, no. (\%) & $4(8 \%)$ & $11(23 \%)$ & 0.05 \\
\hline Gastrointestinal symptoms, no. (\%) & $38(76 \%)$ & $31(65 \%)$ & 0.27 \\
\hline Mucocutaneous symptoms, no. (\%) & $35(70 \%)$ & $27(56 \%)$ & 0.21 \\
\hline Abnormal labs, no. (\%) & $34(68 \%)$ & $37(77 \%)$ & 0.37 \\
\hline Elevated troponin I, no. (\%) & $6(12 \%)$ & $16(33 \%)$ & 0.01 \\
\hline Elevated BNP or proBNP, no. (\%) & $12(24 \%)$ & $20(42 \%)$ & 0.08 \\
\hline $\begin{array}{l}\text { Creatinine estimate glomerular filtration rate }<50 \% \text { of } \\
\text { predicted, no. }(\%)\end{array}$ & $2(4 \%)$ & $5(10 \%)$ & 0.26 \\
\hline Elevated alanine aminotransferase, no. (\%) & $8(15 \%)$ & $18(33 \%)$ & 0.02 \\
\hline Elevated D-dimer, no. (\%) & $27(54 \%)$ & $28(58 \%)$ & 0.69 \\
\hline Elevated partial thromboplastin time, no. (\%) & $4(8 \%)$ & $6(12 \%)$ & 0.52 \\
\hline Elevated procalcitonin, no. $(\%)$ & $10(20 \%)$ & $12(25 \%)$ & 0.63 \\
\hline Leukocytosis, no. (\%) & $14(28 \%)$ & $16(33 \%)$ & 0.66 \\
\hline Thrombocytosis, no. (\%) & $3(6 \%)$ & $6(12 \%)$ & 0.31 \\
\hline Elevated $\mathrm{C}$ reactive protein, no. $(\%)$ & $31(62 \%)$ & $32(67 \%)$ & 0.68 \\
\hline Leukopenia, no. (\%) & $6(12 \%)$ & $6(12 \%)$ & 1 \\
\hline Thrombocytopenia, no. (\%) & $11(22 \%)$ & $22(46 \%)$ & 0.02 \\
\hline Abnormal chest imaging, no. (\%) & $17(34 \%)$ & $33(69 \%)$ & 0.001 \\
\hline Abnormal chest X-ray, no. (\%) & $10(20 \%)$ & $25(52 \%)$ & 0.001 \\
\hline Abnormal CT scan, no. (\%) & $3(6 \%)$ & $8(12 \%)$ & 0.12 \\
\hline
\end{tabular}

$P$ values in bold italics indicate statistical significance $<0.05$ 

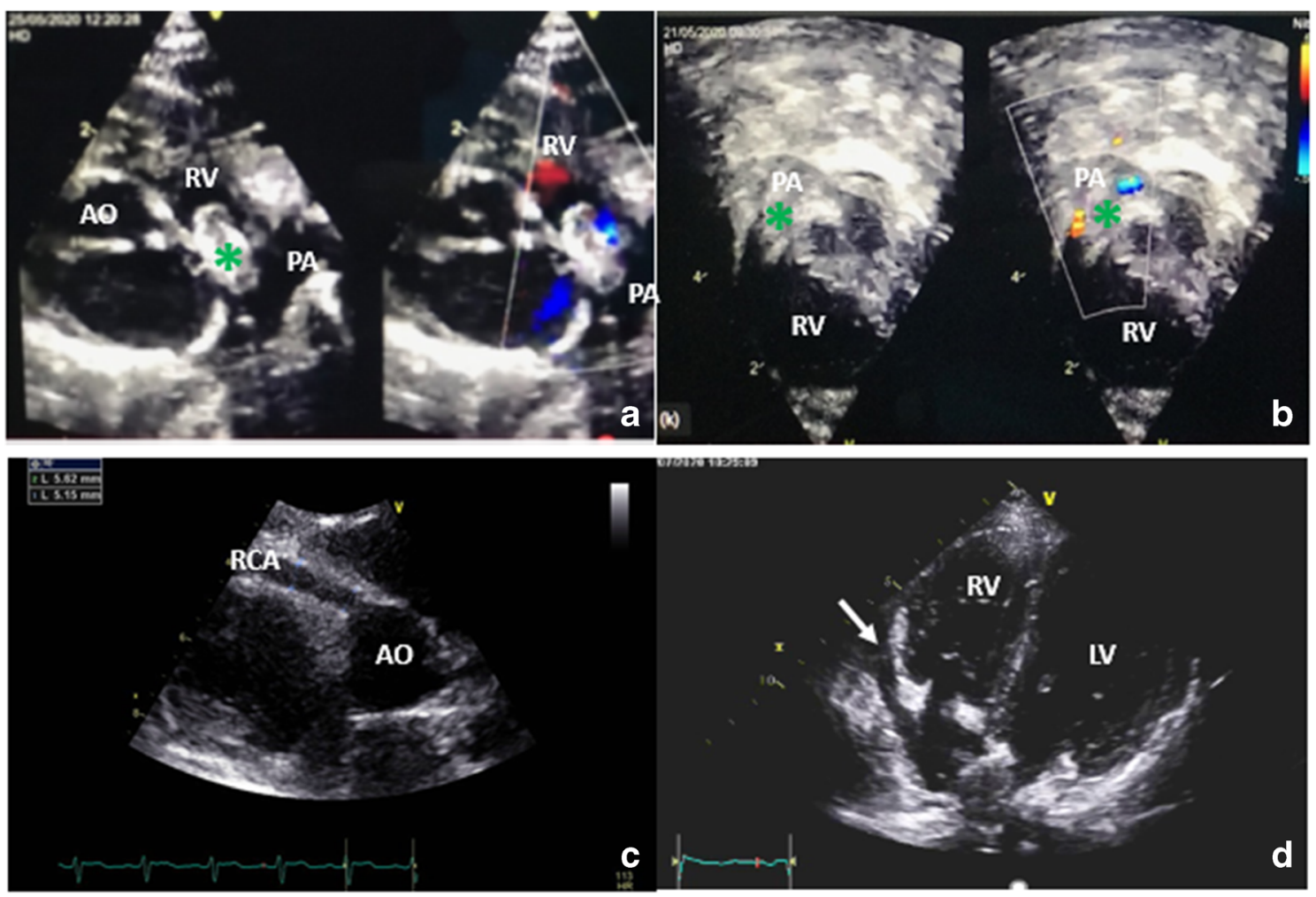

Fig. 1 Echocardiographic manifestations of cardiac involvement: Large thrombus on the main pulmonary artery in situ (denoted by *) on transthoracic echocardiography parasternal short axis view (a) and subxiphoid view (b); right coronary artery dilation on parasternal short-

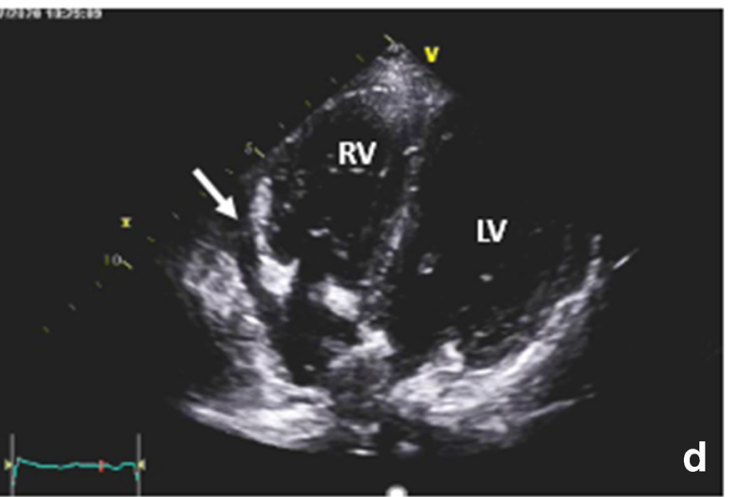

axis view (c); laminar pericardial (denoted by arrow) on apical view (d). Abbreviations: AO aorta, PA pulmonary artery, RV right ventricular, RCA right coronary artery

specificity $50 \%$, positive predictive value $34 \%$, and negative predictive value $96 \%$.

\section{Management}

The cardiac group was more likely to need ICU admission (Table 3). While none received extracorporeal membrane oxygenation support and $27 \%$ of the combined group did not receive IVIg, the cardiac group was more likely to use vasoactive infusions, endotracheal intubation, diuretic therapy, and macrolide antibiotics. Specifically, 27\% of the cardiac group children required vasoactive infusions for systemic perfusion support compared to only $4 \%$ of those in the no cardiac group $(p=0.002)$.

\section{Subgroup analyses}

Of the total group, 32 children (31\%) were 2 years of age or younger, 21 of whom were in the cardiac group. While the limited sample precluded meaningful statistical analysis, within this younger age group, cardiac versus no cardiac children appeared similar in age, weight, male sex, and noncardiac symptom sets, lab testing, chest imaging, and therapies (data not shown). 
Table 3 Cardiac and non-cardiac group involvement

\begin{tabular}{llll}
\hline Management & No cardiac involvement & Cardiac involvement & $p$ value \\
\hline$N$ & 50 & 48 & \\
Admission to ICU, no. (\%) & $27(54 \%)$ & $37(77 \%)$ & $\mathbf{0 . 0 2}$ \\
Antiarrhythmic, no. (\%) & $0(0)$ & $1(2 \%)$ & 0.49 \\
Extracorporeal membrane oxygenation, no. (\%) & 0 & 0 & \\
Diuretic therapy, no. (\%) & $3(6 \%)$ & $19(40 \%)$ & $<\mathbf{0 . 0 0 1}$ \\
Endotracheal intubation, no. (\%) & $2(4 \%)$ & $11(23 \%)$ & $\mathbf{0 . 0 0 7}$ \\
Heparin/low molecular weight heparin, no. (\%) & $10(20 \%)$ & $16(33 \%)$ & 0.17 \\
Vasoactive infusion, no. (\%) & $2(4 \%)$ & $13(27 \%)$ & $\mathbf{0 . 0 0 2}$ \\
Macrolide antibiotic, no. (\%) & $1(2 \%)$ & $9(19 \%)$ & $\mathbf{0 . 0 0 7}$ \\
Intravenous immunoglobulin infusion, no. (\%) & $39(78 \%)$ & $29(60 \%)$ & $\mathbf{0 . 1 1}$ \\
\hline
\end{tabular}

Vasoactive infusion indicates epinephrine, norepinephrine, dopamine, dobutamine, milrinone, or vasopressin

$P$ values in bold italics indicate statistical significance $<0.05$
Of the total group, 23 children (23\%) were SARS COV2 IgG-positive, indicating subacute exposure, with 15 of these being cardiac. Within this group, cardiac versus no cardiac children were similar in age, weight, and sex. Noncardiac symptom sets, lab testing, chest imaging, and therapies were also grossly similar (data not shown). The subsample size precluded more detailed statistical analysis.

\section{Discussion}

This analysis of children from LATAM belonged to a purportedly high-risk race/ethnicity for SARS COV2 infection and sequelae but was drawn from countries with a variety of socioeconomic backgrounds and health systems. In this group selected for multisystem involvement, a substantial proportion were indeed proven to be SARS COV2-positive or SARS COV2-exposed, which demonstrates the global reach of SARS COV2 in the differential diagnosis of multisystem disease. Of these multisystem-affected children, nearly half had clinically significant cardiac involvement including myocarditis, coronary artery dilation, ventricular dysfunction, moderate to severe valvar regurgitation, arrhythmia, one infant with near occlusive main pulmonary thrombus, and one infant mortality. This substantial cardiac involvement was also present in the toddler/infant subgroup as well as those with remote SARS COV2 exposure noted by IgG presence. The cardiac group had more signs and symptoms generally. Specifically, the cardiac group was more likely to have prominent accessory respiratory muscle use, abnormal chest X-ray, and abnormal circulating troponin, ALT, and thrombocytopenia, but not BNP. The cardiac group was more likely to need intensive care including more endotracheal intubation and ventilation, vasoactive infusions, and diuretic therapy. ROCs showed either abnormal troponin or ALT, or thrombocytopenia was highly sensitive with high negative predictive value on the need for ICU interventions. On balance, for LATAM children presenting with multisystem SARS COV2, cardiac involvement was frequent, distinguished by worse respiratory status and cardiac enzyme elevation, thrombocytopenia, and ALT elevation, and led to intensive care support. We are unaware of other reports in LATAM children detailing neither significant multisystem involvement nor the characteristics distinguishing cardiac vs non cardiac involvement.

Contrasting perhaps from previous publications from North American and European LATAM subpopulations, these data are from LATAM children of varying socioeconomic backgrounds and are informative for clinical SARS COV2 management in LATAM children specifically and global health epidemiology generally. Emerging data shows that Hispanic adults as minority populations in certain North American or European populations may or may not be at higher risk of SARS COV2 infection, intensive care admission, or respiratory failure based on high-risk/front-line occupations, age, or other SARS COV2 risk factors such that after adjustment, most of the ethnicityrelated excess risk is attenuated [6]. In this cohort of children, such risk factors were not apparent. In recent pediatric reports, serious consequences of SARS COV2 may be more common in Hispanic children [7]. Unmeasured confounders of genetics, immunologic response, detailed body composition, lifestyle, environment, or other factors cannot be excluded.

SARS COV2 infection is described to have myriad symptoms and complications in children. Early reports in Chinese children had median age 6.7 years and fever in $41 \%$, and only 3 patients required intensive care support and invasive mechanical ventilation all of whom had preexisting conditions [8]. Reports from Italy showed that the median age was 11 years, and $51.4 \%$ of them were males, and the general hospitalization rate was $13.3 \%$, and the ICU admission rate in intensive care unit was $3.5 \%$. Preexisting conditions were present in $10 \%$ of hospitalized patients, and infants had the highest proportion of severe infections [1]. A subsequent multicenter report from the USA describing children needing intensive care showed that the large majority had significant preexisting 
comorbidities and respiratory symptoms, and many had prolonged hospital stays culminating in a few with multiorgan failure and mortality [9]. Early reports from China focusing on infants noted the variable presence of fever and mild respiratory symptoms with none requiring intensive care or severe complications [10]. Recent reports from a European center report a high risk of cardiac involvement and ICU needs as well as elevated biomarkers in SARS COV2-affected children. Our report parallels this previous work and extends it by comparing those with versus without cardiac involvement in LATAM children. The substantial risk of coronary dilation and myocarditis in this pediatric sample deserves special attention. This difference may either reflect the selection for multisystem disease or reflect a susceptibility in this population. A minority of these children had preexisting conditions but still had high proportion involving multiple organ systems while thankfully being spared from mortality. While the proportions with preexisting conditions in cardiac and no cardiac groups were similar, we cannot comment on whether preexisting conditions were overrepresented compared to mild or asymptomatic SARS COV2 as we did not study this type of mild disease. The possible utility of neither troponin versus brain natriuretic peptide nor clinical characteristics has not been previously reported to distinguish cardiac vs noncardiac groups in multisystem disease overall. The studied characteristics' association with cardiac involvement and severity of disease even in infants and toddlers may imply children with multisystem SARS COV2 could be proactively screened for these features in order to detect cardiac involvement and the need for intensive care.

Emergent during this observation period was MISC or alternatively PIMS [4]. MISC is defined by age $<21$ years, fever, laboratory evidence of inflammation, and evidence of clinically severe illness requiring hospitalization, multisystem $(\geq 2)$ organ involvement, SARS CoV2-positive test or exposure, and no alternative plausible diagnoses [11, 12]. PIMS differs by allowing single involvement or multiorgan involvement and with or without positive SARS CoV2 testing [13]. A difficulty of the PIMS/MISC definition set involves the requirement for hospitalization which in low-resource settings may be prohibitive in a child who at presentation has not yet fully manifested the true severity of eventual disease, which then highlights the need for measurable characteristics earlier in disease which may trigger heightened suspicion for intensive management. Many of the children described in our sample would qualify for PIMS/MISC. Cardiac involvement was more common in those children with more systems involved. We found that troponin was associated with cardiac, whereas proBNP elevation was present both in cardiac and no cardiac group, suggesting proBNP may not be an ideal test for discerning cardiac group, but that troponin might be more effective. Troponin elevation and prominent accessory muscle use with abnormal chest X-ray appear to be easily ascertainable and could trigger a noninvasive cardiac workup until better modalities are identified. Likewise, ALT and thrombocytopenia are assayable in a variety of healthcare systems. Identifying the cardiac group is imperative as higher proportions of these children required intensive care. Our ROC analysis found elevated troponin level, or elevated ALT, or thrombocytopenia had strong sensitivity and negative predictive value for the ICU needs. These observational data may serve as a preliminary data for future prospective analyses and screening strategies.

This study had the strengths of being a timely investigation into children from high-risk LATAM nations in a multicenter fashion with wide variation in terms of clinical evaluation and treatment, race/ethnicity, sociodemographic background, and cultural/political milieu. These strengths allowed for the collation and comparison of uncommon characteristics like cardiac involvement and lack of IVIg availability. Limitations include the observational nature of the data collection, precluding causal inference. This analysis is subject to selection bias given the included patients tended to be those requiring hospital presentation. Therefore, the present data cannot be generalized to more mild cases. There is a risk of ascertainment bias insofar as providers in disparate locations were free to examine, test, and treat as per their own practice preferences. However, the data reported herein were at least available to all included centers, making any such differences reflective of provider decision-making rather than feasibility. The rapidly changing medical environment made precise enumeration of acute infection versus multisystem inflammatory syndrome SARS COV2 challenging; however, the precise definitions of these protean syndromes and nuances in SARS COV2 exposure make case definition difficult in general. Emerging indices of SARS COV2 involvement such as interleukins and cardiac MRI were not available at presentation of the children reported herein and thus are unavailable to document more sensitive diagnostic measures. Moreover, this analysis' strength is contextualizing from the perspective of clinical signs and symptoms to inform clinical decisionmaking rather than adherence to a particular theoretical heuristic. Finally, while this analysis involves children with the rich diversity in racial and ethnic heritage present in LATAM, it may not generalize to other populations.

In summary, children from LATAM with multisystem SARS COV2 had nearly $48 \%$ cardiac involvement including in situ large artery thrombi, coronary dilation, ventricular dysfunction, valvar regurgitation, arrhythmia, and unfortunate mortality. These children were distinguished by worse respiratory effort, elevation in cardiac enzymes and ALT, thrombocytopenia, and abnormal chest radiography. These features are useful to ascertain because children with cardiac involvement went on to be more likely to need intensive cares such as invasive mechanical ventilation, vasoactive infusions, and diuretic therapy. Nonetheless, the widely available diagnostic and therapeutic modalities described herein are widely 
available and informative for resource-replete and resourcepoor settings around the globe.

Supplementary Information The online version contains supplementary material available at https://doi.org/10.1007/s00431-021-04052-9.

Authors' Contributions JPZ conceived the study design and data collection tools, analyzed the data, formulated the manuscript, and obtained funding. RHP critically edited the manuscript, deployed and collated data collection tools, and supervised the study. All other authors contributed data to the study and critically reviewed the manuscript.

Funding This work was supported by the SISIAC (Society of Cardiovascular Imaging of the Interamerican Society of Cardiology) (RP) and NHLBI R01 HL148217 (JPZ).

Data availability Relevant, de-identified data can be made available on request.

Code availability Not applicable

\section{Declarations}

Ethics approval This retrospective chart review study involving human participants was in accordance with the ethical standards of the institutional and national research committee and with the 1964 Helsinki Declaration and its later amendments or comparable ethical standards. The Human Investigation Committee (IRB) of CEDIMAT, Dominican Republic approved this study. Other centers either ceded review to this center or exempted from review due to de-identified, retrospective data collection.

Consent to participate Participant consent was exempted by the Ethics Board due to de-identified data collection and collation.

Consent for publication All authors consent to publication of this work. Participant consent was exempted by the Ethics Board due to deidentified data collection and collation.

Conflict of interest The authors declare no competing interests.

\section{References}

1. Bellino S, Punzo O, Rota MC, Del Manso M, Urdiales AM, Andrianou X et al (2020) COVID-19 disease severity risk factors for pediatric patients in Italy. Pediatrics. 146:e2020009399

2. Richardson S, Hirsch JS, Narasimhan M, Crawford JM, McGinn T, Davidson KW, and the Northwell COVID-19 Research Consortium, Barnaby DP, Becker LB, Chelico JD, Cohen SL, Cookingham J, Coppa K, Diefenbach MA, Dominello AJ, DuerHefele J, Falzon L, Gitlin J, Hajizadeh N, Harvin TG, Hirschwerk DA, Kim EJ, Kozel ZM, Marrast LM, Mogavero JN, Osorio GA, Qiu M, Zanos TP (2020) Presenting characteristics, comorbidities, and outcomes among 5700 patients hospitalized with COVID-19 in the New York City Area. JAMA. 323:2052-2059

3. Zhou F, Yu T, Du R, Fan G, Liu Y, Liu Z et al (2020) Clinical course and risk factors for mortality of adult inpatients with COVID-19 in Wuhan, China: a retrospective cohort study. Lancet. 395(10229):1054-1062
4. Levin M (2020) Childhood multisystem inflammatory syndrome - a new challenge in the pandemic. N Engl J Med 383(4):393-395

5. Kim L, Whitaker M, O'Halloran A, Kambhampati A, Chai SJ, Reingold A, Armistead I, Kawasaki B, Meek J, Yousey-Hindes K, Anderson EJ, Openo KP, Weigel A, Ryan P, Monroe ML, Fox K, Kim S, Lynfield R, Bye E, Shrum Davis S, Smelser C, Barney G, Spina NL, Bennett NM, Felsen CB, Billing LM, Shiltz J, Sutton M, West N, Talbot HK, Schaffner W, Risk I, Price A, Brammer L, Fry AM, Hall AJ, Langley GE, Garg S, COVID-NET Surveillance Team, COVID-NET Surveillance Team, Coates A, Daily Kirley P, Libby T, Roland J, Alden N, Herlihy R, McLafferty S, Clogher P, Kayalioglu H, Maslar A, Misiorski A, Niccolai L, Olson D, Parisi C, Fawcett E, Gretzinger S, Lengacher K, Williams J, Blythe D, Brooks A, Park R, Wilson M, ComoSabetti K, Danila R, Cline C, Angeles K, Eisenberg N, Flores K, Habrun C, Hancock E, Khanlian S, Novi M, Phipps E, SalazarSanchez Y, Dufort E, Muse A, Bushey S, Gaitan M, Kurtz RA, Owusu-Dommey A, Snyder L, Michaelis K, Seeley K, Markus T, Chatelain R, George A, Hill M, McCullough L, Spencer M, Swain A, McCaffrey K, Holstein R, Meador S, Wortham J (2020) Hospitalization rates and characteristics of children aged $<18$ years hospitalized with laboratory-confirmed COVID-19 - COVID-NET, 14 states, March 1-July 25, 2020. MMWR Morb Mortal Wkly Rep 69(32):1081-1088

6. Raharja A, Tamara A, Kok LT (2020) Association between ethnicity and severe COVID-19 disease: a systematic review and metaanalysis. J Racial Ethn Health Disparities. 2020 Nov 12:1-10

7. Alsaied T, Tremoulet AH, Burns JC, Saidi A, Dionne A, Lang SM, Newburger JW, de Ferranti S, Friedman KG (2021) Review of cardiac involvement in multisystem inflammatory syndrome in children. Circulation. 143(1):78-88

8. Lu X, Zhang L, Du H, Zhang J, Li YY, Qu J et al (2020) SARSCoV-2 infection in children. N Engl J Med 382(17):1663-1665

9. Shekerdemian LS, Mahmood NR, Wolfe KK, Riggs BJ, Ross CE, McKiernan CA et al (2020) Characteristics and outcomes of children with coronavirus disease 2019 (COVID-19) infection admitted to US and Canadian pediatric intensive care units. JAMA Pediatr 174:868

10. Wei M, Yuan J, Liu Y, Fu T, Yu X, Zhang ZJ (2020) Novel coronavirus infection in hospitalized infants under 1 year of age in China. Jama. 323:1313-1314

11. Feldstein LR, Rose EB, Horwitz SM, Collins JP, Newhams MM, Son MBF, Newburger JW, Kleinman LC, Heidemann SM, Martin AA, Singh AR, Li S, Tarquinio KM, Jaggi P, Oster ME, Zackai SP, Gillen J, Ratner AJ, Walsh RF, Fitzgerald JC, Keenaghan MA, Alharash H, Doymaz S, Clouser KN, Giuliano JS Jr, Gupta A, Parker RM, Maddux AB, Havalad V, Ramsingh S, Bukulmez H, Bradford TT, Smith LS, Tenforde MW, Carroll CL, Riggs BJ, Gertz SJ, Daube A, Lansell A, Coronado Munoz A, Hobbs CV, Marohn KL, Halasa NB, Patel MM, Randolph AG, Overcoming COVID-19 Investigators, CDC COVID-19 Response Team (2020) Multisystem inflammatory syndrome in U.S. children and adolescents. N Engl J Med 383(4):334-346

12. Dufort EM, Koumans EH, Chow EJ, Rosenthal EM, Muse A, Rowlands J, Barranco MA, Maxted AM, Rosenberg ES, Easton D, Udo T, Kumar J, Pulver W, Smith L, Hutton B, Blog D, Zucker H, New York State and Centers for Disease Control and Prevention Multisystem Inflammatory Syndrome in Children Investigation Team (2020) Multisystem inflammatory syndrome in children in New York State. N Engl J Med 383(4):347-358

13. Whittaker E, Bamford A, Kenny J, Kaforou M, Jones CE, Shah P, Ramnarayan P, Fraisse A, Miller O, Davies P, Kucera F, Brierley J, McDougall M, Carter M, Tremoulet A, Shimizu C, Herberg J, Burns JC, Lyall H, Levin M, for the PIMS-TS Study Group and EUCLIDS and PERFORM Consortia (2020) Clinical characteristics of 58 children with a pediatric inflammatory multisystem 
syndrome temporally associated with SARS-CoV-2. JAMA. 324: 259-269
Publisher's note Springer Nature remains neutral with regard to jurisdictional claims in published maps and institutional affiliations.

\section{Affiliations}

Ricardo Pignatelli ${ }^{1}$. Clara Vazquez Antona ${ }^{2}$. Ivan Romero Rivera ${ }^{3}$. Patricia Alvarez Zenteno ${ }^{4} \cdot$ Yanet Toribio Acosta ${ }^{5}$. Manuel Huertas-Quiñones ${ }^{6} \cdot$ Carlos Alvarez Murillo $^{7}$. Franklin Mendoza Torres ${ }^{7} \cdot$ Carlos Fernandez Cabalin $^{8}$. Ana Galván Camacho ${ }^{9}$. Alex Alcántara Pérez ${ }^{10}$. Ana Braga Lombardi ${ }^{11}$. Andressa Mussi Soares ${ }^{12}$. Carolina Torres Garcia ${ }^{13}$. Cibelle Teixeira Borges ${ }^{14}$. Claudia Natalia Villalba ${ }^{15} \cdot$ Cristhian Ramírez Lechado $^{16}$. Deborah Trevisan Dias ${ }^{17}$. Diana Aravena Morales ${ }^{18}$. Elizabeth Mora Copete ${ }^{19}$. Guillermo Larios Goldenberg ${ }^{20}$. Jahaira Sussety Salazar ${ }^{21}$ • Jessica Alchundia Moreira ${ }^{21}$ • Junko Asakura ${ }^{22}$. Karla Solórzano Sabando ${ }^{21}$. Klebia Castello Branco ${ }^{23}$ • Lida Toro Rosas ${ }^{10}$. Magna Pereira Duarte ${ }^{24}$. María Jiménez Carbajal ${ }^{25}$. Martha Rubio Hernandez ${ }^{26}$. Moisés Mier Martínez ${ }^{27}$. Nancy Garay Echeverría ${ }^{28}$. Olga Maza Caneva ${ }^{29}$. Patricia Romero Sepulveda ${ }^{30}$ - Paulina Agurto Díaz ${ }^{18}$ - Ruth Rugel Plúas ${ }^{31}$ • Theo Contreras Alvarado ${ }^{32}$. Lorena Tapia Faundes $^{33}$ • Yeny Briones Diaz ${ }^{18}$. Justin P. Zachariah ${ }^{1}$

\author{
Ricardo Pignatelli \\ cardiop@bcm.edu \\ Clara Vazquez Antona \\ cvazquezant@yahoo.com.mx \\ Ivan Romero Rivera \\ irrivera@uol.com.br \\ Patricia Alvarez Zenteno \\ pazenteno@yahoo.com \\ Yanet Toribio Acosta \\ jantor85@gmail.com \\ Manuel Huertas-Quiñones \\ manuelhuertasmd@gmail.com \\ Carlos Alvarez Murillo \\ doccalvarezm@hotmail.com \\ Franklin Mendoza Torres \\ franklinmendozaipnc@gmail.com \\ Carlos Fernandez Cabalin \\ cfernandez@sochicar.cl \\ Ana Galván Camacho \\ dra.karen.galvan.alergologa@gmail.com \\ Alex Alcántara Pérez \\ alexalcantarap@gmail.com \\ Ana Braga Lombardi \\ analuizabragabm@hotmail.com \\ Andressa Mussi Soares \\ amussisoares@gmail.com \\ Carolina Torres Garcia \\ ctorres.2278@gmail.com \\ Cibelle Teixeira Borges \\ cibelletb@gmail.com \\ Claudia Natalia Villalba \\ villalbacn76@gmail.com \\ Cristhian Ramírez Lechado \\ Cristinoram@Hotmail.com
}

\author{
Deborah Trevisan Dias \\ trevisancardio@gmail.com \\ Diana Aravena Morales \\ dianaaravenam@gmail.com \\ Elizabeth Mora Copete \\ elimorac@gmail.com \\ Guillermo Larios Goldenberg \\ gqlarios@uc.cl \\ Jahaira Sussety Salazar \\ susety22@hotmail.com \\ Jessica Alchundia Moreira \\ dra.jessicaneumoinfantil@gmail.com \\ Junko Asakura \\ junkoxabo@yahoo.com.br \\ Karla Solórzano Sabando \\ drakarlasolorzano@gmail.com \\ Klebia Castello Branco \\ klebiacb@gmail.com \\ Lida Toro Rosas \\ lidatoro@gmail.com \\ Magna Pereira Duarte \\ magnardo@hotmail.com \\ María Jiménez Carbajal \\ mgjcmed@yahoo.com.mx \\ Martha Rubio Hernandez \\ martharubio2003@yahoo.com.mx \\ Moisés Mier Martínez \\ dr_mier@hotmail.com \\ Nancy Garay Echeverría \\ nancygareche@ hotmail.com \\ Olga Maza Caneva \\ omazacaneva@gmail.com \\ Patricia Romero Sepulveda \\ patriciar_2487@hotmail.com
}


Paulina Agurto Díaz

paulinadoc@gmail.com

Ruth Rugel Plúas

mipretty_rut@hotmail.com

Theo Contreras Alvarado

theoyca@ hotmail.com

1 Section of Pediatric Cardiology, Department of Pediatrics, Baylor College of Medicine, Texas Children's Hospital, 6651 Main St Legacy Tower 20th Floor, Houston, TX 77030, USA

2 Instituto Nacional de Cardiología Ignacio Chavez, Ciudad de México, México

3 Universidad Federal de Alagoas, Maceio, Brazil

4 Hospital Dr. Roberto del Río, Santiago, Chile

5 CEDIMAT, Santo Domingo, Dominican Republic

6 Fundación Cardioinfantil Cardiology Institute, Bogota, Colombia

7 Instituto Nacional de Salud del Niño San Borja, Lima, Perú

8 Clinica Santa María, Santiago, Chile

9 Hospital Militar de Especialidades, Ciudad de México, México

10 Complejo Asistencial Dr. Sótero del Río, Santiago, Chile

11 Universidad Federal do Rio Grande do Norte, Natal, Brazil

12 Hospital Evangélico de Cachoeiro de Itapemirim, Cachoeiro de Itapemirim, Brazil

13 Centro Policlinico Olaya, Bogotá, Colombia

14 Hospital São Camilo Cura Dar's, Fortaleza, Brazil

15 Hospital Británico, Buenos Aires, Argentina

16 Hospital Solidaridad, Managua, Nicaragua

Lorena Tapia Faundes

lorenaisabeltapia@gmail.com

Yeny Briones Diaz

yeny.brione@gmail.com

17

18

19$$
\text { Centro Pediátrico del Corazón ABC-Kardias, Ciudad de }
$$
México, México

Real Hospital Português de Beneficência, Recife, Brazil Hospital Dr. Luis Calvo Mackenna, Santiago, Chile Clínica La Colina, Bogotá, Colombia

Pontificia Universidad Católica de Chile, Santiago, Chile Hospital de Especialidades, Portoviejo, Ecuador Hospital UNIMED, Maceio, Brazil Universidade Federal do Ceará, Fortaleza, Brazil Hospital Geral do Estado de Alagoas, Maceio, Brazil Centro Médico ABC, Ciudad de México, México Hospital Central Dr. Ignacio Morones, San Luis Potosí, México Hospital General Pediatrico Acosta Nu, Asunción, Paraguay Clínica General del Norte, Barranquilla, Colombia CEDIMAT, San Cristobal, Dominican Republic Omnihospital, Guayaquil, Ecuador IMSS Hospital de Cardiología No. 34, Monterrey, México Departamento de Pediatria Norte, Facultad de Medicina, Universidad de Chile, Santiago, Chile 